\title{
A Review: Effect of Laser Peening Treatment on Properties And Life Cycle of Different Materials
}

\author{
Navjot Singh*, Krishna Ahuja,Tarandeep singh, Sandeep Singh \\ Mechanical Engineering Department, DAV Institute Of Enginerring \& Techonolgy Jalandhar, Punjab, India
}

\begin{abstract}
In this review, the effect of laser peening process with and without protective coating is discussed over the different material and it is observed that the residual stress are induced in material surface up to some depth according to process parameters of LSP. Fatigue strength and micro-hardness of material are enhance by inducing residual stresses which further depends on process parameters and material properties.
\end{abstract}

Keywords:- laser peening proces, different material, process parameters

\section{Introduction}

Due to increase trend all over the world to utilize the material up to extreme levels in all the fields, various methods has been developed and successfully applied. Similarly, Improvement of material surface now a day is an integral part of industrial operations, mechanical and metallurgical properties of material has to be improved i.e. fatigue strength, toughness and corrosion resistance for long life of material. Light amplification by simulation emission (LASER) is used for many manufacturing process such as laser drilling, laser cutting and laser welding. For modify the material surface properties laser peening technique is used. Laser peening is the new surface alteration technique, which is the beneficial alternative of shot peening method [1]. Laser peening is used in aerospace and automotive industries [2].LSP is surface modification technique has been in existence for over last 25-30 years. In laser shock, peening process laser in pulse mode is use to strike over the material surface, which creates plasma, and produce the shock waves due to that compressive residue stresses are formed in the material surface for some depth. LSP is more flexible process used to modify variety of material such as tough metals, soft metals etc.LSP produce residual stress 3-4 times deeper as achieved in shot peening process and surface finish is higher than SP.

\section{A. Laser peening with coating:-}

The key phenomenon behind the laser peening is that high energy laser in pulse mode for small duration is impacted over the material surface which is cover with a ablative absorbent layer which get evaporate under the action of high energy laser beam and the plasma is created at that point which is trapped by a transparent layer such as water, which raise the pressure at that spot so that shock waves are produced when the pressure of shock waves is exceed the hugoniot elastic limit of material, the plastic distortion take placed due to that compressive residual stresses are produced in material surface as shown in fig. 1. Hong et al. stated that black paint layer absorb almost 100\% of laser energy [3].

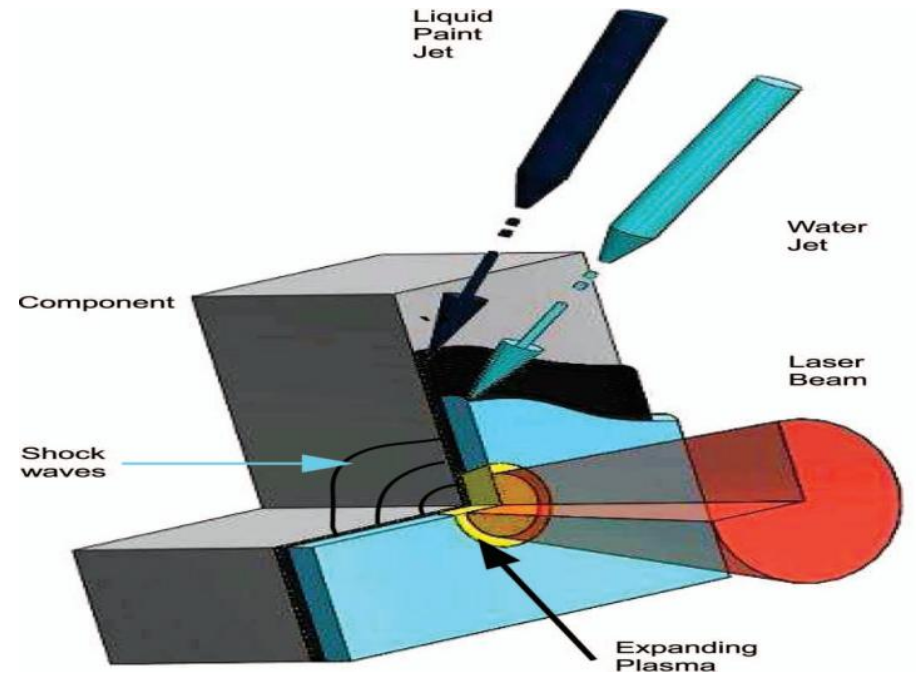

Fig. 1 Schematic of an LSP process-showing overlay in place and the laser beam irradiating the material surface [10]. 


\section{B. Laser peening without coating:-}

For laser shock peening without coating double frequencies Nd: YAG laser is used which impacted low energy per pulse on material surface. In LPwC laser at low energy is impacted over the surface, so that high pressure plasma generated by laser pulse irradiation with minimum thermal heat production. Laser with low energy has chance to vary the overlapping conditions. LPwC is used to reduce tensile stress and Implement the compressive residual stress in material surface layers [4-6].LPwC is not required any protective coating, by tuning the process parameters melting and re-solidification of material surface can avoid [7-9]. For prevent the material from stress corrosion cracking $\mathrm{LPwC}$ is commonly used.

\section{Literature Review}

M. Obata et al [11] optimized the process parameters of laser peening by appraising the compressive residual stress in material interior and at surface of cold worked stainless steel 304 and stated that for maximum compressive residual stress spot size (Ds) $0.8 \mathrm{~mm}$, pulse number density (Np) 3600 pulse $\mathrm{cm}^{-2}$ and pulse energy (Ep) $200 \mathrm{Mj}$ are most suitable .It was concluded that for $20 \%$ cold worked stain less steel there is stress improvement in material, practically compressive stress layer of over $1 \mathrm{~mm}$ is formed, there is no effect of material strength over the compressive stress depth profile and the compressive residual stress produce by laser peening reduce the corrosion cracking due to stress, occurrent in corrosive high temperature water as shown in fig 2.

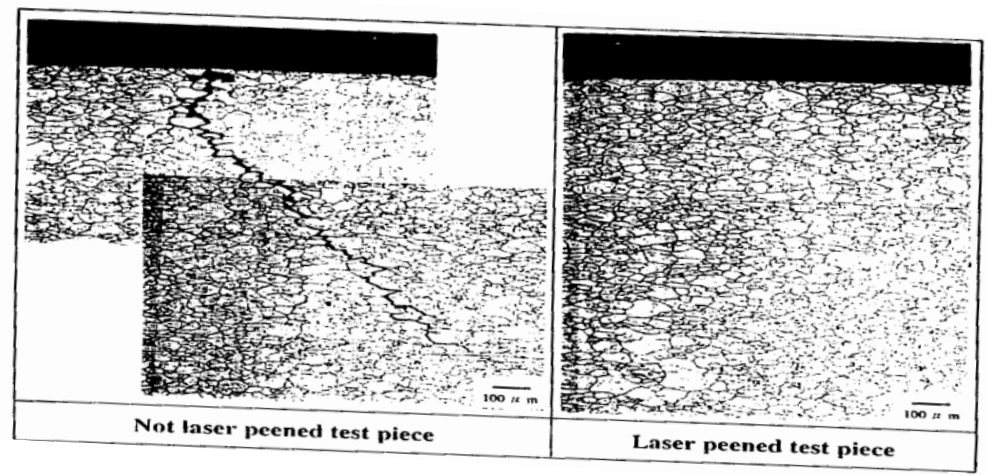

Fig. 2 microstructure on the cross section of the test pieces after stress corrosion cracking tests $\left(.8 \mathrm{~mm} / 200 \mathrm{~mJ} / 3600\right.$ pulse $\left.\mathrm{cm}^{-2}\right)[11]$

Y.X. Hu et al [12] investigated by using finite element method analysis that the overlapping laser shock increased the compressive residual stress in material produced by shock waves while using laser shock peening technique for modify the surface properties of material and it has no effect on the plastically affected depth . The overlapping impact sequence has great effect on affected zone or residual stress zone and to obtain the homogenous residual stress field, diminished the occurrence of 'residual stress hole' by impacting the key area first. The overlapping rate has influence over the compressive residual stress, the $25 \%$ overlapping rate increased the residual stress by $25.5 \%, 50 \%$ overlapping rate increased the residual stress by $34.8 \%$ and $75 \%$ overlapping rate increased the stress by 40.2 as shown in Fig. 3

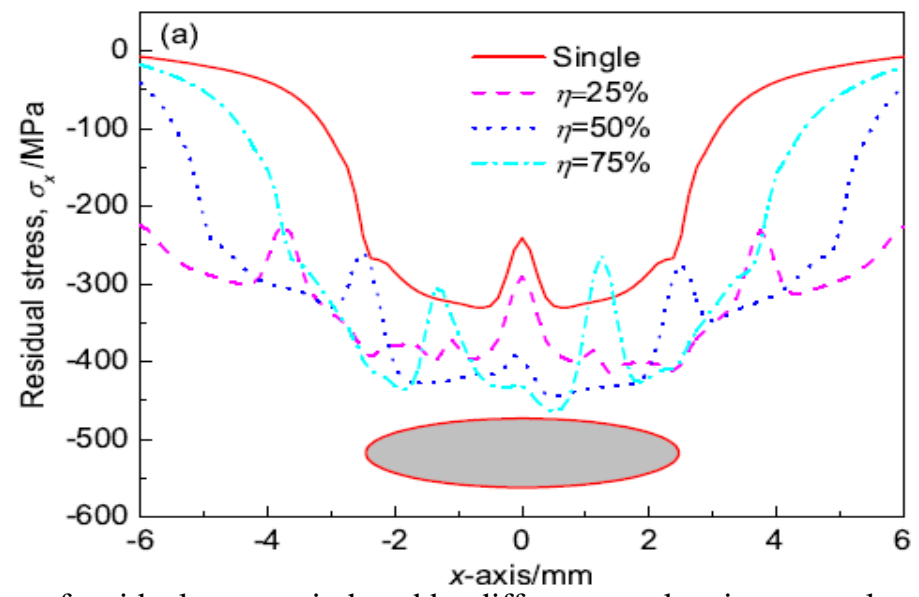

Fig. 3 FEM simulation of residual stresses induced by different overlapping rates along $x$-axis on top surface [12] 
Qiao Hongchao et al [13] stated that surface roughness of TiAl alloy which is treated by laser shock peening at 1064 wavelength, 0-10 pulse energy , $18 \mathrm{~ns}$ pulse duration and $2 \mathrm{~Hz}$ frequency, increased by increasing pulse energy and peening times as shown in Fig. 4. The micro hardness of Ti-Al alloy improved by increasing the pulse energy, because plastic deformation, fine grains and high density dislocation are produced on the surface of material due to high shock waves but the impact of shock waves are gradually reduce along the depth of surface so that micro hardness of alloy is decreased gradually towards depth of material from surface as shown in Fig. 5

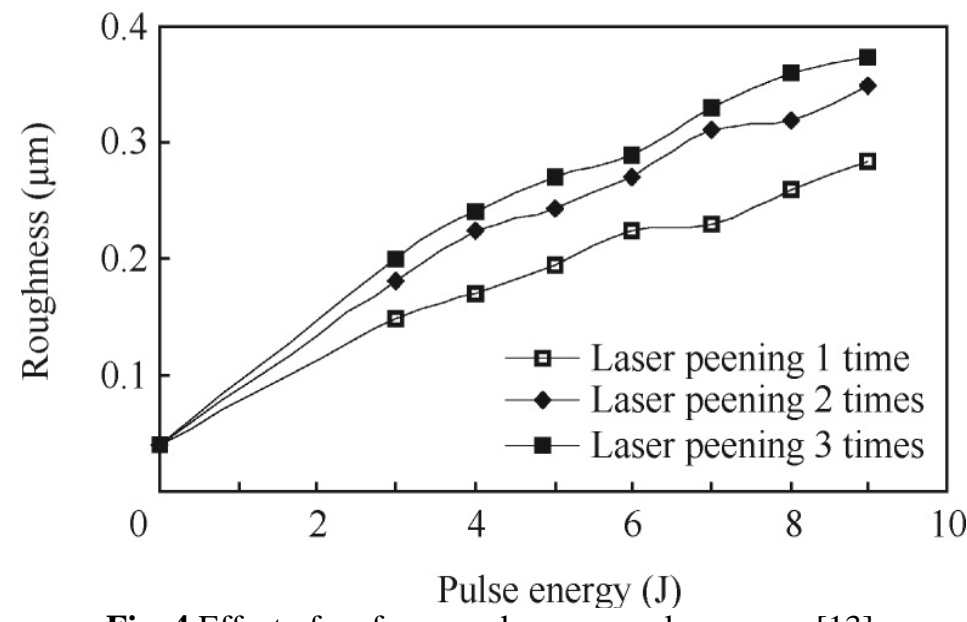

Fig. 4 Effect of surface roughness on pulse energy [13]

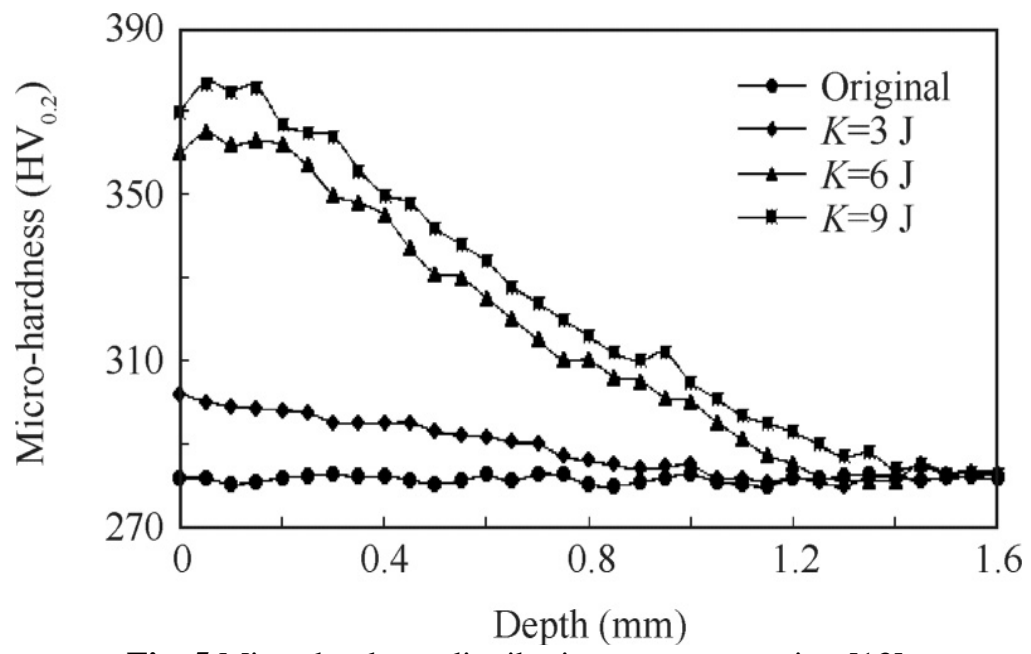

Fig. 5 Micro-hardness distribution on cross-section [13]

The compressive residual stress are also improved by increasing the pulse energy because the fine grain, new grain boundaries and dislocation are formed due to high shock energy .compressive stress increased from $15 \mathrm{MPa}$ to $337 \mathrm{MPa}$ after laser peening, the pulse energy and residual stresshas same relation as relationship between micro hardness and pulse energy. They also states that the compressive residual stress, micro hardness, and microstructure formed by LSP method has higher stability.

Michael r. Hill et al [14] investigated the behavior of residual stress towards the depth of $20 \mathrm{~mm}$ thick alloy 22 (UNS N06022) square plate which was treat by laser shock peening process with the multiple peening layers (2, 4,10 and 20) at $25 \mathrm{~ns}$ pulse duration and $120 \mu \mathrm{m}$ thick ablative layer was used, they also investigated the identical depth for all peening layers at which residual stress are equal to $20 \%$ yield strength of material. It was concluded that the identical depth at $20 \%$ yield strength are same for all samples except the two layers of peening as shown in Fig.6. They also investigated the behavior of residual stress produced in alloy 22 plates, join with double $\mathrm{v}$ grooved GTAW weld which also treated with laser peening process and compare with non treated joint. It was concluded that near the surface all residual stress are tensile or zero for non treated specimen(as welded) and near equal -300MPa for laser treated specimen. A uniform deep layer of compressive stress is formed in treated region. 


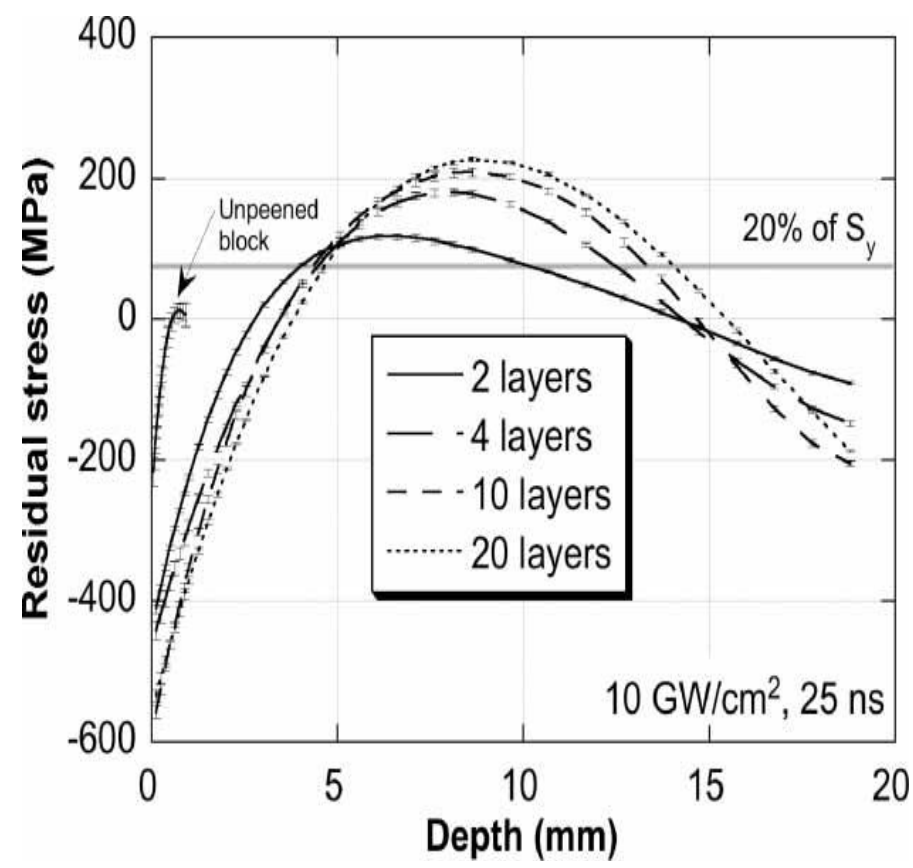

Fig. 6 Residual stress versus depth for LSP blocks showing the effect of the number of layers on the residual stress profile [14]

Yoshihiro Sakino et al[15] examined the effect of pulse energy on residual stress induced in SM400 and HT780 which were treated by laser peening using Nd:TAG under the conditions shown in table 1.It was concluded that when the energy of pulse was decreased the surface residual stress and maximum compressive stress produced in SM400 were same as produced in SM400 with $200 \mathrm{~mJ}$ pulse energy shown in Fig.7(a) \& (b).In case of HT780 by reduction in pulse energy the residual stress were also reduce in both directions longitudinal and normal, but at the low pulse energy there were large amount of compressive residual stress in material as shown in Fig. 7(a)\&(b).They also considered the effect of pulse energy on fatigue life and concluded that by reducing pulse energy fatigue life of material is also reduce respectively.

Table 1 laser peening condition [15]

\begin{tabular}{|l|l|l|l|l|}
\hline $\begin{array}{l}\text { Pulse } \\
\text { energy } \\
(\mathrm{mJ})\end{array}$ & $\begin{array}{l}\text { Spot } \\
\text { diameter } \\
(\mathrm{mm})\end{array}$ & $\begin{array}{l}\text { Irradiation density } \\
\left(\text { pulse } \mathrm{mm}^{-2}\right)\end{array}$ & $\begin{array}{l}\text { Cumulative } \\
\text { Energy } \\
\text { Density } \\
\left(\mathrm{MJ}^{-2} \mathrm{~m}^{-2}\right.\end{array}$ & $\begin{array}{l}\text { Peak } \\
\text { power } \\
\text { density } \\
\left(\mathrm{TW} \cdot \mathrm{m}^{-2}\right)\end{array}$ \\
\hline 200 & 0.8 & 36 & 7.2 & 50 \\
\hline 50 & 0.45 & 72 & 3.6 & 39 \\
\hline 20 & 0.3 & 144 & 2.9 & 35 \\
\hline
\end{tabular}

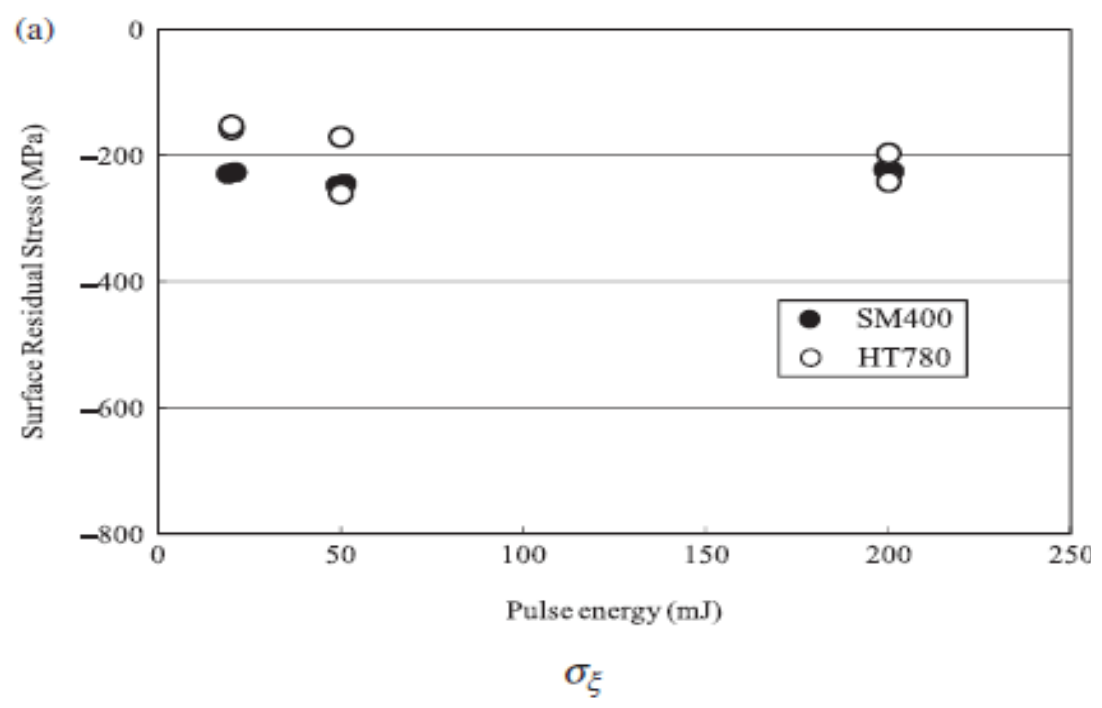




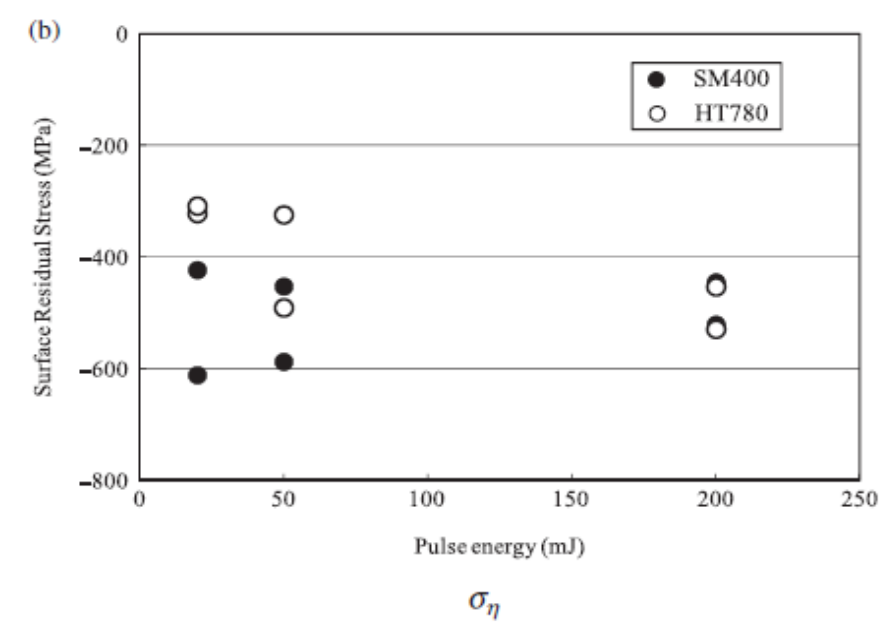

Fig.7 (a) \& (b) Relation between laser pulse energy and residual stress [15]

R. Sundar et al [17] observed that black PVC tape was more effective sacrificial tape instead of adhesive backed tapes and green PVC tape. It was also investigated that use of black polyvinyl chloride tape instead of black paint as adherent sacrificial coating while laser peening treatment on different material provide less rough surface. Three different materials Ti6A14V alloy, SAE 9260 spring steel and DIN X20Cr13 martensitic stainless steel were treated with laser shock peening process by using blank paint and black PVC tape. It was concluded that by using black PVC tape there was no melting of material surface and the surface was more smooth rather than surface obtained by using black paint. There was no change in surface roughness during LSP with black PVC tape, and deeper compressive residual stress layers were formed in material rather than with black paint. Black PVC tape was more commercial and easily available; it facilitates the quick application and reduces the overall processing time.

Tang yaxin et al [18] investigated the effect of laser peening treatment on the aluminum alloy 2024-T62 and used polyvinylidene fluoride (PVDF) transducer to measure the stress waves induced in material surface during LSP. A Q-switched Nd: glass with $1.06 \mu \mathrm{m}$ wavelength and pulse duration of $30 \mathrm{~ns}$ was used in LSP and induced peak pressure was 1.2-2.2 GPa which was higher than the Hugoniot Elastic Limit of 2024-T62 of 0.53 GPa. It was concluded that when the higher power density LSP with short duration was used the peak pressure was more than the hugoniot elastic limit of material as a result of that the fatigue strength and the fatigue life of material was increased by 4.5 to 9.8 times than that of un-shocked material surface. LSP results in surface hardness increased the compressive strength and dislocation density of residual stresses layers.

Sanja Petronic et al [19] investigated the effect of picoseconds laser shock peening on the microstructure of super alloy Nimonic263 at wavelength of $1064 \mathrm{~nm}$ and $532 \mathrm{~nm}$, the various parameters for laser treatment was shown in table 2.It was concluded that after LSP treatment microstructure was fine and more uniform rather than parent material surface. At different wavelength, different impact on material properties was observed, there was fine structure and lower roughness surface formed with the laser of $1064 \mathrm{~nm}$ wavelength rather than laser of $532 \mathrm{~nm}$ wavelength but there was unwanted phases induced during the treatment with laser of $1064 \mathrm{~nm}$ wavelength which induced crack formation. With an increment in pulse energy and no. of pulse, the pores start to generate and create a coral like structure in microstructure obtained at $532 \mathrm{~nm}$ wavelength and fine structure was obtained for pulse energy $10 \mathrm{~mJ}$ in microstructure formed at $1064 \mathrm{~nm}$ wavelength by further increasing the pulse energy above $200 \mathrm{~mJ}$ melting of surface starts. At end it was stated that picoseconds LSP was improved the micro-hardness of nimonic263.

Table 2 Estimated values of highest pressure for different pulse energy at two different wavelengths.

\begin{tabular}{|l|l|l|l|l|l|l|}
\hline Wavelength (nm) & \multicolumn{2}{|l|}{531} & 1064 \\
\hline $\begin{array}{l}\text { Pulse energy } \\
(\mathrm{mJ})\end{array}$ & 25.0 & 30.3 & 35.0 & 2.0 & 10.1 & 15.0 \\
\hline $\begin{array}{l}\text { Power } \\
\begin{array}{l}\text { Density } \\
\left(\mathrm{GW} \mathrm{cm}^{-2}\right)\end{array}\end{array}$ & 0.65 & 3.32 & 5.0 & 1.95 & 2.42 & 2.89 \\
\hline $\begin{array}{l}\text { Peak pressure } \\
(\mathrm{GPa})\end{array}$ & 2.23 & 2.45 & 2.78 & 1.31 & 2.93 & 3.64 \\
\hline
\end{tabular}


B.K Pant el al [20] found out the practical application of laser peening on turbine blades. Due to increase in trend of higher efficiencies, there is an increase in working temperature and size of turbine due which the chance of fatigue failure of turbine blades also rises. It was investigated the advantages of laser surface peening on shot peening on behalf of fatigue test and x-ray diffraction test conducted on the titanium 6/4 alloy and stainless steel 420. Two sets of each specimen of dimensions $(50 \mathrm{~mm}$ x $50 \mathrm{~mm}$ x $6 \mathrm{~mm}$ ) were treat with Nd: YAG "Q" switched type laser of $2.5 \mathrm{~J}$ flash lamp with 125 micrometer insulated black tape pasted on specimen and another ablative coating of water was used on insulated tape. Various process parameters of shot peening and laser peening are show in table $7 \& 8$. It was conclude that laser peening was better than shot peening and increases the material life by increasing the fatigue strength as shown in fig. 8 and induced deeper residual stress as shown in fig. 9 (a) $\&(b)$.

Table 7 Parameters of shot peening

\begin{tabular}{llllll}
\hline $\begin{array}{l}\text { Shot dia, } \\
\mathrm{mm}\end{array}$ & $\begin{array}{l}\text { Nozzle } \\
\text { dia, mmm }\end{array}$ & $\begin{array}{l}\text { Distance between } \\
\text { nozzle and specimen, } \\
\mathrm{mm}\end{array}$ & $\begin{array}{l}\text { Air } \\
\text { pressure, } \\
\mathrm{kg} / \mathrm{cm}^{2}\end{array}$ & $\begin{array}{l}\text { Peening } \\
\text { time, s } s\end{array}$ & $\begin{array}{l}\text { Almen } \\
\text { intensity }\end{array}$ \\
\hline $0.7-0.9$ & 8 & $175-225 \mathrm{~mm}$ & $2.5-3$ & $5-6$ & $0.3-0.35$ \\
\hline
\end{tabular}

Table 8 Parameters of Laser Peening

\begin{tabular}{|c|c|c|c|c|c|}
\hline $\begin{array}{l}\text { Pulse energy } \\
\text { (J) }\end{array}$ & $\begin{array}{l}\text { Pulse } \\
\text { duration } \\
\text { (ns) }\end{array}$ & $\begin{array}{l}\text { Repetition } \\
\text { rate (Hz) }\end{array}$ & $\begin{array}{l}\text { Spot } \\
\text { diameter } \\
(\mathrm{mm})\end{array}$ & $\begin{array}{l}\text { Scan } \\
\text { speed } \\
(\mathrm{mm} / \mathrm{s})\end{array}$ & $\begin{array}{l}\text { Track-to-track } \\
\text { displacement } \\
(\mathrm{mm})\end{array}$ \\
\hline 1.5 & 7 & 2 & 1.5 & 1.75 & 0.7 \\
\hline
\end{tabular}




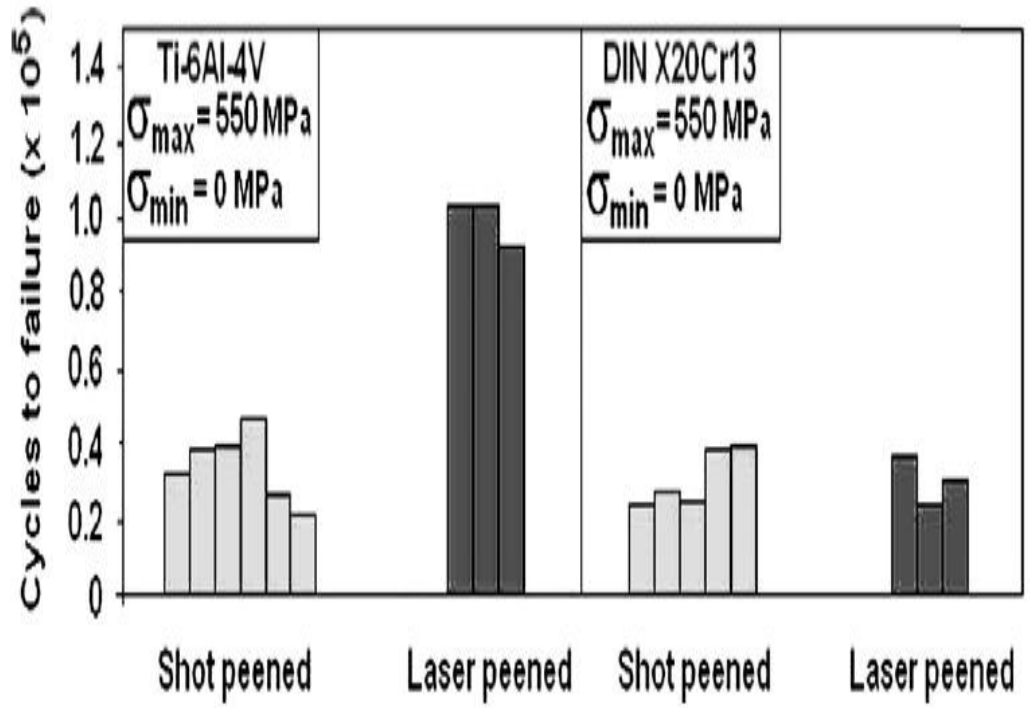

Fig.8 Fatigue Strength induced by LSP and SP [20]

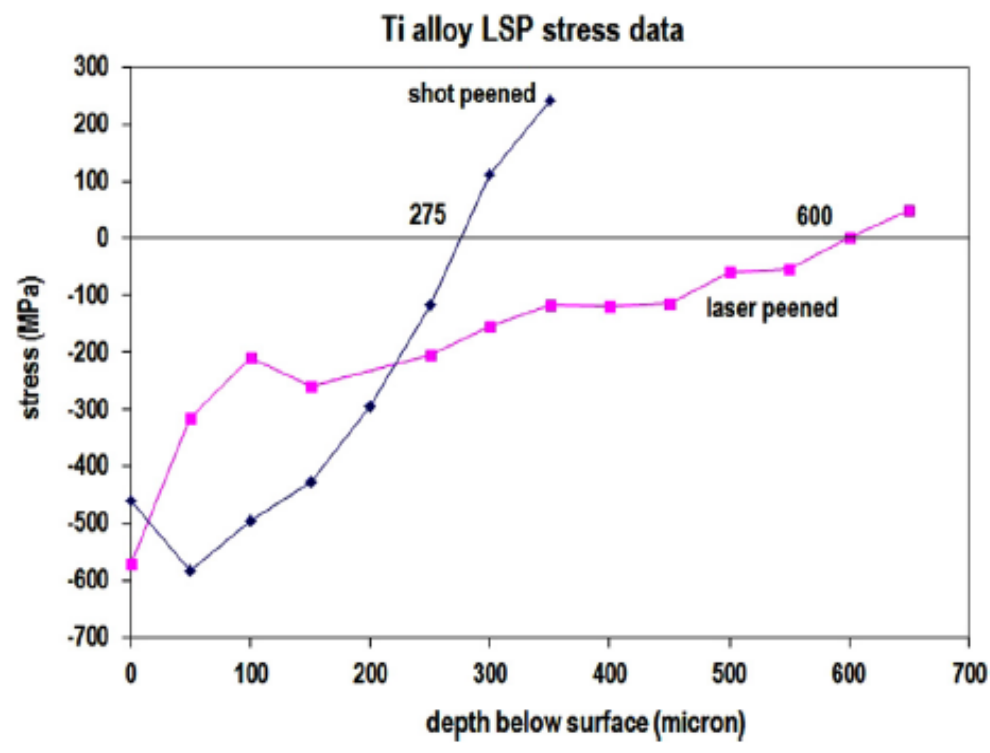

Fig.9 (a) Effect of LSP and SP on titanium alloy [20] 


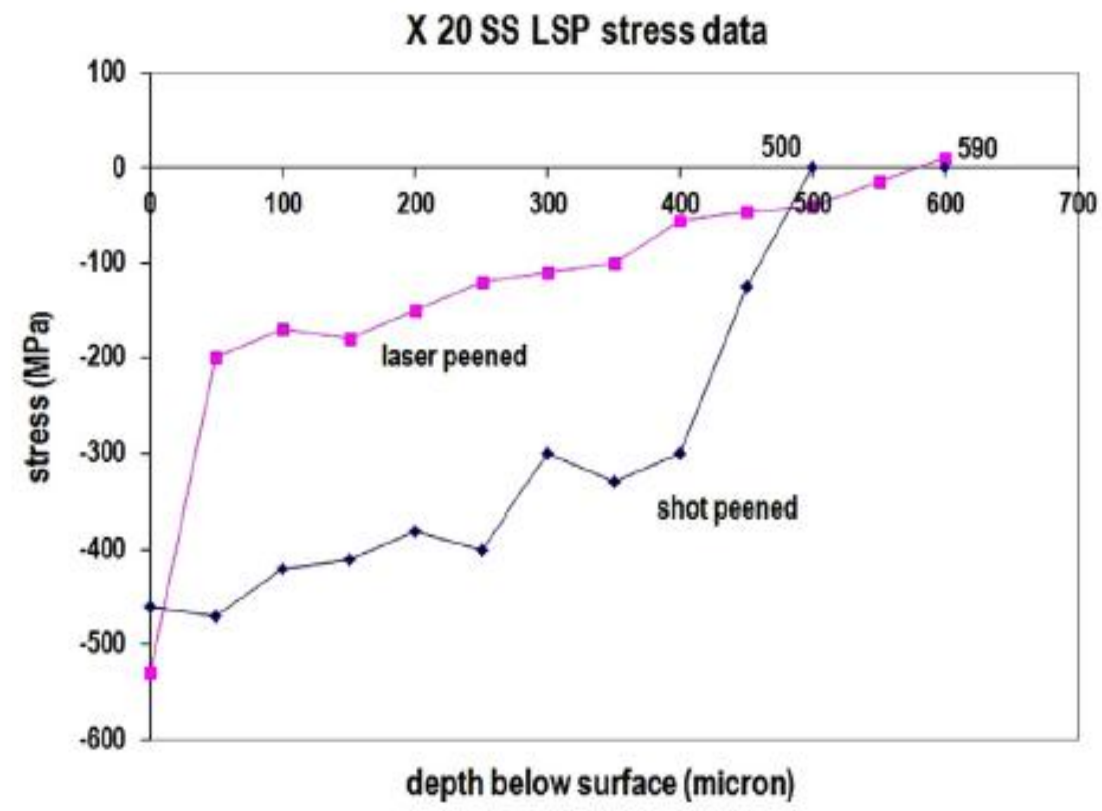

Fig.9 (b) Effect of LSP and SP on SS420 [20]

Chang YE et al [21] studied over the warm laser surface peening which were the extension of the laser peening and another method of increasing the fatigue life. During the warm laser surface peening dynamic precipitation and strain, aging was perform on sample of AISI 4140 of dimension $76 \mathrm{~mm} \times 10 \mathrm{~mm} \times 2.78 \mathrm{~mm}$ and tempering was done. With the WLSP glass, BK7 was use as confining media due to its high melting point and high shock impedance instead of water. Thin aluminum oil was use as the ablative coating. Chang ye et al compare the WLSP and LSP process by conducting micro-hardness test, fatigue strength test and XRD test for check induced residual stresses.

It was concluded that there was no major difference seen in XRD test which depicts that the depth in which stresses penetrates were independent of temperatures and micro-hardness was more at each point in WLSP but Fatigue life was improved by WLSP for the high cycle regime than low cycle regime. The stress cycle curve for bending stress was performed on the machine of $100 \mathrm{KN}$ fatigue testing machine and result was shown in fig. 10

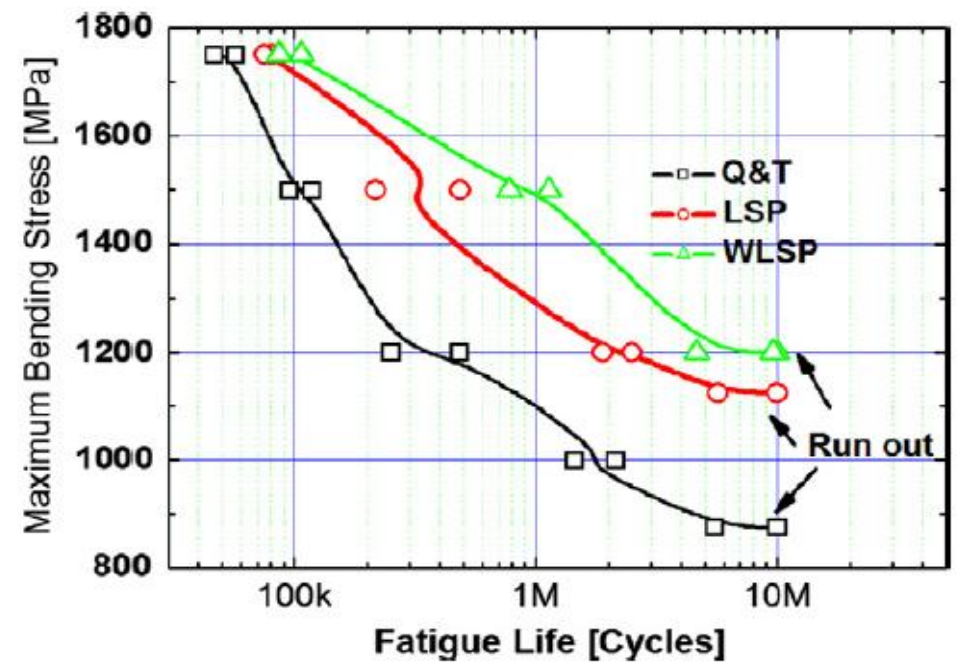

Fig.10 S-N Curve for the AISI 4140 sample [21]

Another great work was done by Omar Hatamleh et al [22] in increasing the fatigue life of the aluminum 7075-T7351 friction stir welded sample. The fatigue life of laser peened sample was compare with the shot peened sample. The specimen of $122 \mathrm{~cm} \times 40 \mathrm{~cm} \times 0.635 \mathrm{~cm}$ was welded with friction stir welding. Five different samples were selected which were treated with - no peening, shot peening process, base, single layer laser peening and tripled layer peening. It was concluded that fatigue life of FSW specimens was improve by treating with 3 layers LSP process rather than non-treated and SP treatment. It was clearly shown by Fig.11 that 
crack propagation in no treated specimen was fast and in 3 layers treated specimen was very slow compare to other specimens.

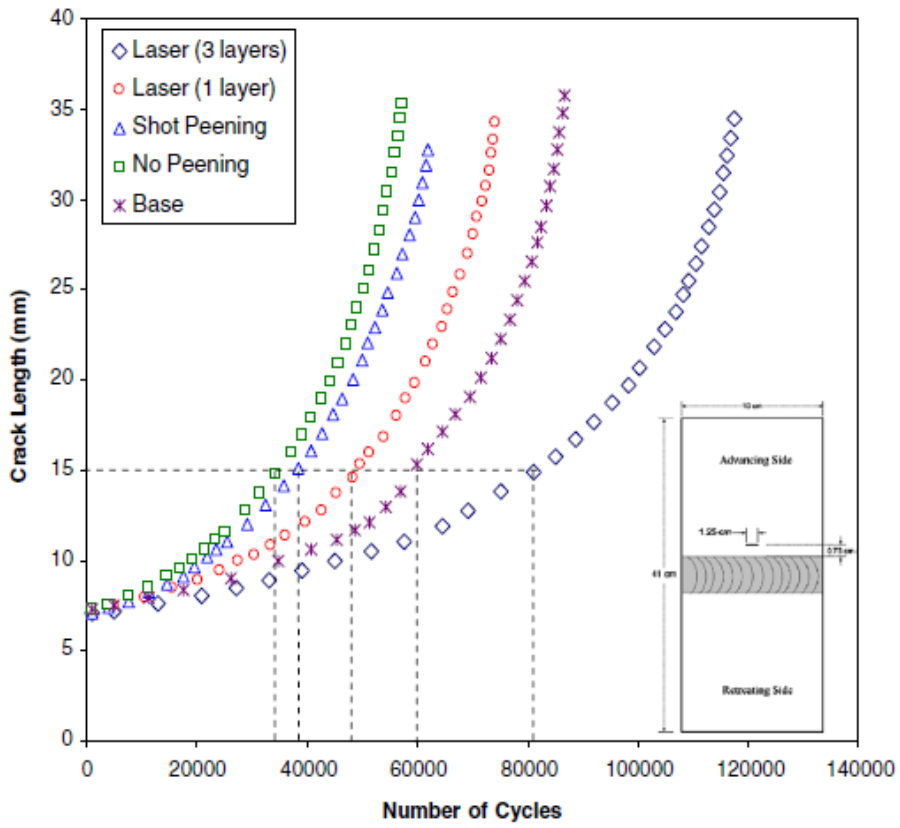

Fig.11 crack length v/s no. of cycles for the Aluminum 7075-T7351 [22]

John J. Ruschau et al [23] investigated the fatigue crack growth rate of the laser peened Ti6/4 and the unprocessed specimens. The typical blade material sample of Ti6/4 of diameter $44.5 \mathrm{~mm}$ was annealed by the argon gas quenching. Fractographic investigations was done to calculate the difference in the crack growth rate behavior due to LSP and it was observed that the fatigue failure of the unprocessed sample is similar to other metals in which crack initiation is started at the notch tip which is machined and turn to failure under continuous fatigue load.

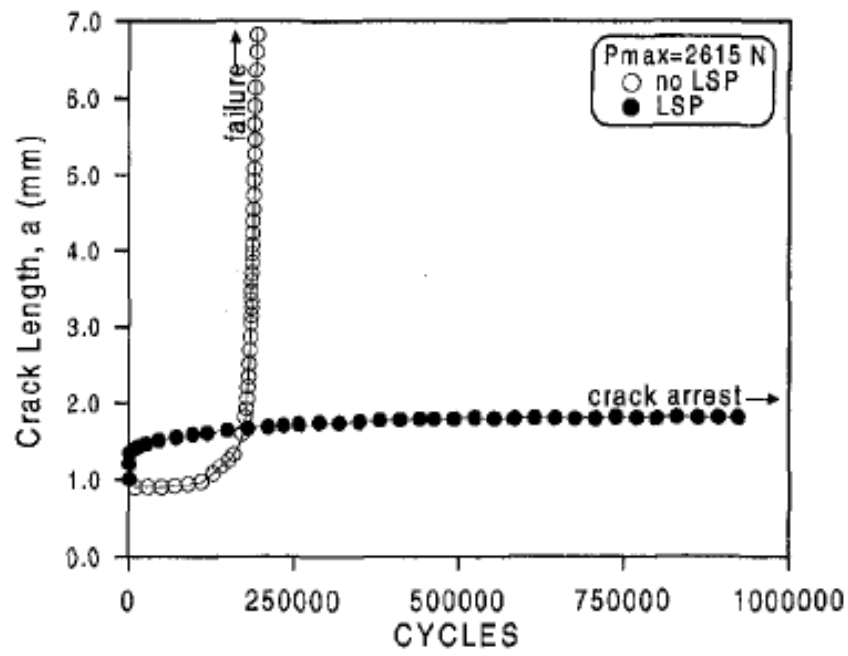

Fig.12 Comparison of baseline and LSP crack length versus cycles behavior [23]

Fig.12 depicts that the crack growth was monotonically increased function, means that the stress intensity factor which was applied, was in raising crack length for a granted load, even if thickness of the specimen increases with crack length. In contrary to this fatigue crack growth behavior of the sample shows that crack began under similar loading conditions increase for small distance then arrested. This phenomenon was repeated again and again, that was reinitiated crack and then arrested. This can show through the A versus cycles diagram fig.13. It was concluded that LSP has a remarkable fatigue improvement due to compressive residual stress retained in the depth of the material. 


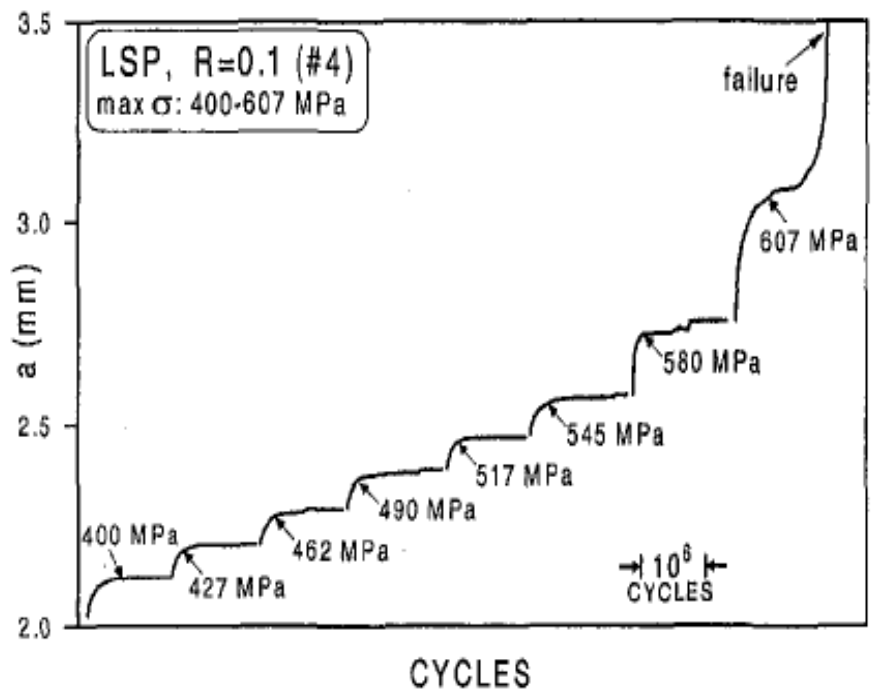

Fig.13 A versus N behavior for single LSP sample [23]

Chang Ye et al [24] changes the previous scenario of performing the LSP at the room temperature by taking inspiration from the WLSP performed on the aluminum alloys, which improves the fatigue life and compressive residual stress stability, and thinks to perform the laser dynamic peening on the metallic materials and hence, chose the copper as investigating sample. Along with experimental setup, FEM was also performed to forecast the distortion nature. The FEM was used to study the effect of heat on the plastic distortion behavior during the LSP, for example plastic affected spot, energy absorption and stress \& strain distribution. LSP performed at the different elevated temperatures by using Q- switched Nd: YAG laser with $1064 \mathrm{~mm}$ wavelength and pulse width of $5 \mathrm{~ns}$. An OFHC copper plate of dimensions of $4 \mathrm{~mm} \times 10 \mathrm{~mm} \times 20 \mathrm{~mm}$, BK7 glass and aluminum foil used as ablative and confining media.LSP done on three different temperatures $300 \mathrm{~K}, 440 \mathrm{~K}$ and $500 \mathrm{~K}$ for investigation.

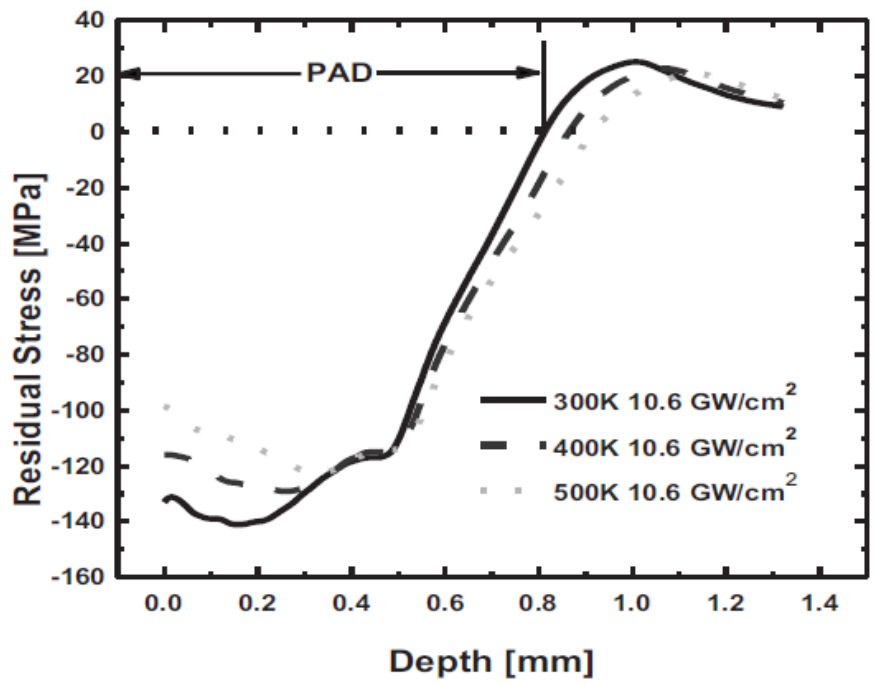

Fig.14 Compressive residual stresses with depth at different temperatures [24]

It was concluded that the deformation of the surface increases with the increment in the laser intensity and temperature. The amount of the residual stresses increases with the decrease in the temperature and increase in the laser intensities. The equivalent plastic deformation with temperature and laser intensity and the plastic deformation penetrate much deeper into the materials at higher temperatures. Also, the depth of residual stress distribution increase with the enhancing laser intensity and temperature as shown in Fig.14. Yasuo Ochi et al [25] considered the effect of LSP treatment without coating on rolled aluminum alloy A7050-T7451, which was treated with Q switched Nd:YAG laser of half wavelength produced by second harmonic generator, laser impacted on surface with spot size of $1.2 \mathrm{~mm}$ diameter, pulse energy of $100 \mathrm{~mJ}$ and pulse number density of 18 pulse $\mathrm{mm}^{-2}$. Axial fatigue tests with ratio -1 and 0.1 were performed and it was concluded that laser peening treatment without coating increase the surface hardness and surface roughness. It also enhance the fatigue 
strength of material in range of $\mathrm{Nf}=4.2 \times 104 \sim 1.8 \times 106$ cycles, but decreased the strength over the life range for the both conditions of $\mathrm{R}=-1.0$ and 0.1 . It also observed that laser peening without coating was effective for maintaining the surface crack propagation behavior.

Chang ye et al [26] investigated over the steel 304 by treated it with LSP process at cryogenic temperatures and normal. Surelite III Q-switched Nd-YAG Laser of wavelength of $1064 \mathrm{~nm}$ and with a pulse width of 5ns was used on $3 \mathrm{~mm}$ thick sample of steel. The size of the laser beam was $1 \mathrm{~mm}$ and 4, 6, 8, 10, $12 \mathrm{GW} / \mathrm{cm}^{2}$ as laser intensities were used. Aluminum foil of thickness 30micrometeres was use as ablative coating and BK7 glass used as confining media. During the Cryogenic LSP the sample fixture was submerged in the liquid nitrogen for about 10 minutes. The author had conducted the micro hardness test and concluded that CLSP had highest hardness among the 3 samples, which is because CLSP generates a higher volume of fraction of marten site than the room temperature LSP as show in fig. 15.

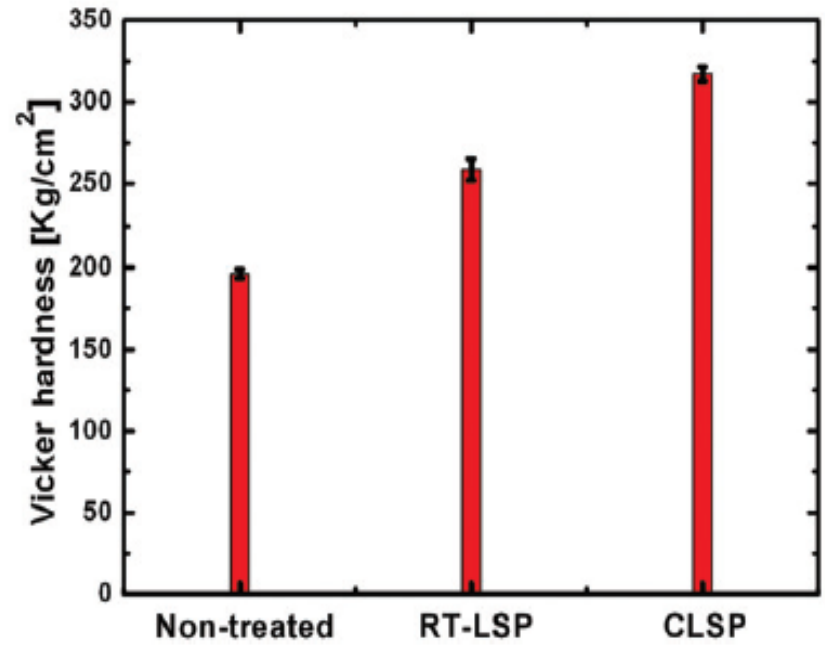

Fig.15 Surface hardness after RT-LSP and CLSP at same Laser intensity [26]

3 point bending test is also conducted and reports a remarkable improvement of samples, which are CLSP and RT-LSP than the non treated sample. The fatigue strength increases from $950 \mathrm{MPa}$ for the non- treated to 1050MPa for the RT-LSP. Similarly increase of strength from 1050MPa to 1100MPa for CLSP for 1 million cycles respectively shown in fig. 16. This is probably due to increase in the chemical driving force and an increase in the density of potential embryos at the cryogenic temperature for the marten- site nucleation's which results in higher compressive residual stresses.

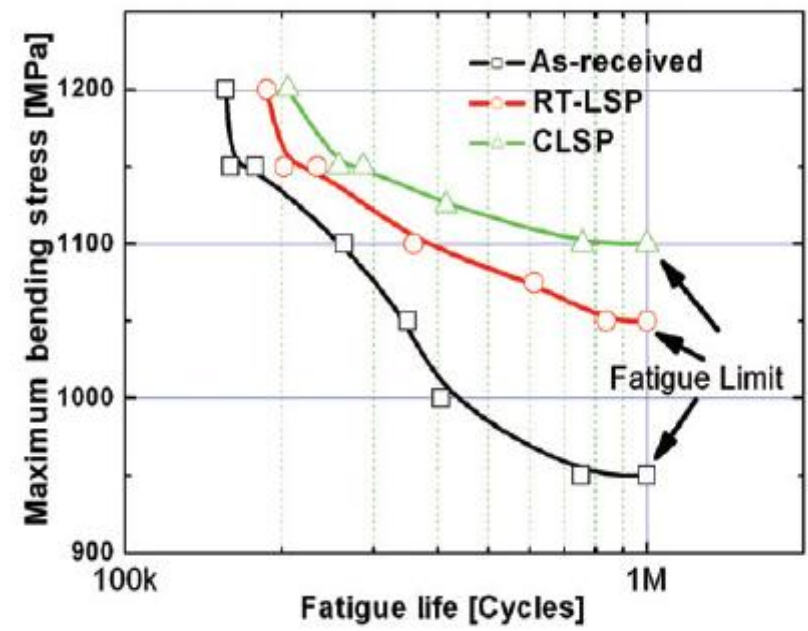

Fig.16 S-N diagram for different samples

III. Conclusion 
Laser peening is process which improves the life cycle of material as survey from the literature. It is clear that residual stresses are induce in material surface during LSP treatment, which enhanced the microhardness of material surface and produced compressive residual stresses, which increase the fatigue strength as investigated in different experiment. It is concluded that laser peening process is better than shot peening process and upgrade the material properties and increase its life cycle.

\section{References}

[1]. Chang Ye a, Sergey Suslov a, Dong Lin a \& Gary J. Cheng a Deformation-induced martensite and nanotwins by cryogenic laser shock peening of AISI 304 stainless steel and the effects on mechanical properties

[2]. P. Ganesh, R. Sundar, Harish Kumar, Rakesh Kaul , K. Ranganathan, P. Hedaoo, PragyaTiwari,etal., Studies onlaserpeeningofspringsteelforau to motive applications, Opt.LasersEng.50(5)(2012)678-686.

[3]. Y. Zhang et al., Laser shock processing of FCC metals, Springer Series in Ma- terials Science, 179, DOI: 10.1007/978-3-64235674-2_2.

[4]. Hong, X.; Wang, S.; Guo, D.; Wu, H.; Wang, J.; Dai, Y.; Xia, X.; Xie, Y. Confining medium and absorptive overlay: Their effects on a laser-induced shock wave. Opt. Lasers Eng. 1998, 29, 447-455.

[5]. Y.Sano, M.Mukai, K.Okazaki and M.Obata. Nuclear Instrument and Methods in Physics Research B, 1997;121:432-436.

[6]. M.Obata, T.Kubo, Y.Sano, M.Yoda, N.Mukai, S.Shima and K.Kanno, Journal of the Society of Materials Science, Japan 2000; 49:193-9.

[7]. Y.Sano, M.Kimura, K.Sato, M.Obata, A.Sudo, Y.Hamomoto, S.Shima, Y.Ichikawa, H.Yamazaki, M.Naruse, S.Hida, T.Watanabe and Y.Oono. Proc. of the 8th Inter. Conf. on Nuclear Engineering(ICONE 8), 2000.

[8]. Yuji Sano, Koichi Akita, Kiyotaka Masaki, Yasuo Ochi, Igor Altenberger, Berthold Scholtes., Laser peening without coating as a surface enhancement technology, Pulse 100 (40) (2006) $250 \mathrm{~mJ}$.

[9]. S. Sathyajith, S.Kalainathan, Effectoflasershotpeeningonprecipitation hardened aluminumalloy6061-T6usinglowenergylaser, Opt.LasersEng.50 (3) (2012)345-348.

[10]. Sathyajith,S.Kalainathan,S.Swaroop.,Laserpeeningwithoutcoatingon aluminum alloyAl- 6061T6usinglowenergyNd: YAGlaser, Opt.LaserTech- nol. 45(2013)389-394.

[11]. Gulshan Singh, Ramana V. Grandhi, and David S. Stargel, Modeling and Parameter Design of a Laser ShockPeening Process, International Journal for Computational Methods in Engineering Science and Mechanics, 12:233-253, 2011.

[12]. M. obata, Y. Sano and N. Mukai,E feecvt of laser peening on residual stress and stress corrosion cracking for type 304 stainless steel , the $7^{\text {th }}$ international conference of shot peening.

[13]. Y.X. Hu and Z.Q. Yao, Fem Simulation Of Residual Stresses Induced By LaserShock with Overlapping Laser Spots, Acta Metall. Sin.(Engl. Lett.) Vol.21 No.2 pp125- 132 april 2008

[14]. Qiao Hongchao, Zhao Jibin, Gao Yu, Experimental investigation of laser peening on TiAl alloy microstructure and properties, Chinese Journal of Aeronautics, (2015),28(2):609-616

[15]. MICHAEL R. HILL, ADRIAN T. DEWALD, JON E. RANKIN, The Role of Residual Stress Measurement in the Development of Laser Peening, Journal of Neutron Research, December 2003 Vol. 11 (4), pp. 195-200

[16]. Sakino Y, Yoshikawa K, Sano Y, Kim Y-C. Effect of peening condition on residual stress imparted by laser peening. Preprint of the National Meeting of JWS. 2010.p. 196-197 (in Japanese).

[17]. Sakino Y, Yoshikawa K, Sano Y, Sumiya R, Kim Y-C.Effects of laser peening condition on residual stress and fatigue life. Proceedings of national symposium on welding mechanics and design 2011. 2011. p. 391-397 (in Japanese).

[18]. R. Sundar, H. Kumar, R. Kaul, K. Ranganathan, P. Tiwari, L. M. Kukreja andS. M. Oak, Studies on laser peening using differentsacrificial coatings, Surface Engineering 2012 Vol. 28 No. 8

[19]. Tang Yaxin, Zhang Yongkang, Zhang Hong, Yu Chengye, Effect of Laser Shock Processing (LSP) on the Fatigue Resistance of an Aluminum Alloy, Journal of Engineering Materials and Technology JANUARY 2000, Vol. 122

[20]. Sanja Petronic, Tatjana Sibalija, Meri Burzic , Suzana Polic, Katarina Colic and Dubravka Milovanovic, Picosecond Laser Shock Peening of Nimonic 263 at1064 nm and $532 \mathrm{~nm}$ Wavelength, Metals 2016, 6, 41; doi:10.3390/met6030041

[21]. B.K. Pant, R. Sundar, Harish Kumar b, R.Kaul, A.H.V.Pavan , K.Ranganathan, K.S. Bindra, S.M.Oak, L.M.Kukreja, RaghuV.Prakash, M.Kamaraj Studies towards development of laser peening technology for martensitic stainless steel and titanium alloys for steam turbine applications

[22]. Chang Ye, Sergey Suslov, Bong Joong Kim, Eric A. Stach, Gary J. Cheng Fatigue performance improvement in AISI 4140 steel by dynamic strain aging and dynamic precipitation during warm laser shock peening.

[23]. Omar Hatamleh, Jed Lyons, Royce Forman. Laser and shot peening effects on fatigue crack growth in friction stir welded 7075T7351 aluminum alloy joints

[24]. John J. Ruschau, reji john, steven R. Thompson, Theodore nicholos, Fatigue Crack Growth Rate Characteristics of Laser Shock Peened Ti-6AI-4V

[25]. Yasuo Ochi, Takashi Matsumura, Takaaki Ikarashi, Kiyotaka Masaki, Toshifumi Kakiuchi, Yuji Sano and Takafumi Adachi, Effects of laser peening treatment without protective coating on axial fatigue property of aluminum alloy, Procedia Engineering 2 (2010) 491-498

[26]. Chang ye, Gary J. Cheng. Effect of temperature on laser shock induced plastic deformation: the case of copper 